\title{
Age-dependent changes in protease and elastase production in cultures of Pseudomonas aeruginosa
}

\author{
S. UMEKI
}

\begin{abstract}
Division of Respiratory Diseases, Department of Medicine, Kawasaki Medical School, 577 Matsushima, Kurashiki, Okayama 701-01, Japan
\end{abstract}

\begin{abstract}
Summary. The intracellular and extracellular protease and elastase contents of Pseudomonas aeruginosa were studied in relation to the age of the culture. The intracellular protease and elastase content of the organisms decreased as the culture grew older, whereas extracellular protease and elastase greatly increased $24 \mathrm{~h}$ after incubation commenced, suggesting that host tissue injury by $P$. aeruginosa infection may increase in proportion to the duration of tissue colonisation.
\end{abstract}

\section{Introduction}

The extracellular proteases of Pseudomonas aeruginosa (alkaline protease and elastase) are considered to be important virulence factors in several human infections caused by this opportunist pathogen (Sabath, 1980). Woods et al. (1981) noted an important role of protease activity in the adherence of $P$. aeruginosa to mammalian buccal epithelial cells. Furthermore, $P$. aeruginosa elastase is of interest on account of its ability to produce corneal ulcers (Kreger and Grey, 1978), necrotic skin lesions (Meinke et al., 1970) and pulmonary haemorrhages (Kreger and Gray, 1978) and to inactivate the human plasma $\alpha_{1}$-proteinase inhibitor (Morihara et al., 1979).

In the present study, age-dependent changes in the intracellular and extracellular excretion of protease and elastase by cultures of $P$. aeruginosa were investigated.

\section{Materials and methods}

\section{Pseudomonas cultures}

$P$. aerúginosa strain $\mathrm{TN}-1$ was isolated from a bronchiectatic patient suffering from pseudomonal pneumonia (Kawasaki Medical School Hospital, Kurashiki, Japan). It was lyophilised and stored at $-70^{\circ} \mathrm{C}$ until use. Before each experiment lyophilised bacteria were inoculated into $25 \mathrm{ml}$ of Mueller-Hinton broth-(/L) beef extract $19.75 \mathrm{~g}$, casamino acids $1.15 \mathrm{~g}$, bacto-soluble starch $0.10 \mathrm{~g}$-and incubated for $18 \mathrm{~h}$ at $37^{\circ} \mathrm{C}$. $P$. aeruginosa $\mathrm{TN}-1$, initially adjusted to $(1-2) \times 10^{5} \mathrm{cfu} / \mathrm{ml}$, was grown in $25 \mathrm{ml}$ of Mueller-Hinton broth at $37^{\circ} \mathrm{C}$ with

Received 26 May 1988; accepted 18 July 1988. continuous shaking $(60 \mathrm{cycles} / \mathrm{min})$ in a temperature gradient bio-photorecorder Model TN-112D (Toyo Kagaku Sangyo Co. Ltd, Tokyo). Organisms were harvested at the early exponential $\left(1.1 \times 10^{6} \mathrm{cfu} / \mathrm{ml}\right.$, after incubation for $2 \mathrm{~h}$ ), mid-exponential $\left(1.1 \times 10^{7} \mathrm{cfu} / \mathrm{ml}\right.$ after $\left.4 \mathrm{~h}\right)$ and late exponential $\left(8.6 \times 10^{8} \mathrm{cfu} / \mathrm{ml}\right.$ after $\left.8 \mathrm{~h}\right)$ phases, and at the early stationary $\left(1.0 \times 10^{10} \mathrm{cfu} / \mathrm{ml}\right.$ after $\left.18 \mathrm{~h}\right)$ and late stationary $\left(1.2 \times 10^{10} \mathrm{cfu} / \mathrm{ml}\right.$ after $\left.24 \mathrm{~h}\right)$ phases. At the specified time, a sample of the culture was centrifuged at $4000 \mathrm{~g}$ for $30 \mathrm{~min}$ and the protease and elastase contents of the supernate were measured. The pellet was washed twice with sodium phosphate-buffered saline (PBS, pH 7.4), resuspended in PBS and disintegrated in 2-ml portions by ultrasonic treatment for $1 \mathrm{~min}$ with the microtip of a Branson sonifier (Model W-200P) set at no. 2. The pellet solution was used for the measurement of intracellular protease and elastase.

Protein concentration was determined according to the method of Lowry et al. (1951) with bovine serum albumin as the standard.

\section{Protease assay}

Generally, supernate and pellet protease contents were assayed by a hide powder azure dye-release method (Rinderknecht et al., 1968); $0.1 \mathrm{ml}$ of the culture supernates (or pellets) and $4.9 \mathrm{ml}$ of $0.01 \mathrm{M}$ Tris buffer (pH 8.0) were incubated with $20 \mathrm{mg}$ of remazol brilliant blue hide powder for $45 \mathrm{~min}$ at $37^{\circ} \mathrm{C}$ in a shaking waterbath. The reactions were terminated by cooling with iced water and the reaction mixture was centrifuged for $5 \mathrm{~min}$ at $2000 \mathrm{~g}$. In the resultant supernates, the absorbance of dye released by protease was measured at $595 \mathrm{~nm}$.

\section{Elastase assay}

Elastase content was assayed in the same manner except that $0.25 \mathrm{ml}$ of each culture supernate (or pellet 
solution) was incubated with $20 \mathrm{mg}$ of orcein-elastin in $2.5 \mathrm{ml}$ of Tris buffer ( $\mathrm{pH} \mathrm{8.0)}$ ) with shaking for $90 \mathrm{~min}$. The reactions were stopped by cooling with iced water and the reaction mixtures were centrifuged for $5 \mathrm{~min}$ at $2000 \mathrm{~g}$. In the resultant supernates, released orcein was measured as absorbance at $590 \mathrm{~nm}$ (Johnson et al., 1967).

The following chemicals were obtained from commercial sources: Trizma base, bovine serum albumin, trypsin, and elastase (Sigma Chemical Co., St Louis, MO.); Mueller-Hinton broth (Difco Laboratories, Detroit, MI.); remazol brilliant blue hide powder/azure, elastin-orcein (Nakarai Chemicals Ltd., Kyoto, Japan). Other chemicals were of the highest purity available from commercial sources.

\section{Results}

Fig. 1 shows changes in the supernate and pellet protein contents with the age of the culture. Although there were no significant changes in the supernate protein content with age, the pellet protein content $/ 10^{6} \mathrm{cfu}$ gradually decreased. Fig. 2 shows age-dependent changes in the supernate and pellet protease contents. Whereas the supernate protease content greatly increased with the age of the culture, by the stationary phase, the pellet protease content had decreased to $20 \%$ of its content in the early exponential phase. In addition, the supernate elastase content greatly increased at the stationary phase (fig. 3). In the stationary phase, the pellet elastase content decreased to $65 \%$ of its content at the mid-exponential phase. Pellet elastase decreased less than pellet protease with the age of the culture (figs. 2 and 3 ).

\section{Discussion}

As reported previously (Kanungo, 1980; Umeki et al., 1983), older cultures are generally characterised by a reduction in physiological activity and a reduced ability to respond to environmental changes. The availability of nutritional factors modifies the physiological state of many microorganisms (Umeki and Wozawa, 1983). Banno et al. (1982) reported that Tetrahymena, a ciliate protozoan, secreted large amounts of intracellular protease into its culture medium as the culture aged. The extracellular proteases of $P$. aeruginosa, an opportunist pathogen which causes fatal infections in the immunocompromised host (Feigin and Shearer, 1975), have been purified by various investigators Morihara and Tsuzuki, 1977; Wretlind and Wadström, 1977). However, little has been reported about changes in the contents of intracellular and extracellular proteases in relation to the age of the culture. This micro-organism secretes several extracellular enzymes that contribute to its pathogenesis, including at least two proteases, elastase and alkaline protease. In the present study, changes in the intracellular contents of $P$. aeruginosa protease and elastase and their secretion into the culture medium in relation to the age of the culture were investigated.

Our results showed age-related increases in extracellular and decreases in intracellular protease and elastase content. $P$. aeruginosa rarely causes infection in immunocompetent hosts, even though the micro-organism may be present in the gastrointestinal and upper respiratory tracts or on the skin. $P$. aeruginosa lung infections, however, fre-

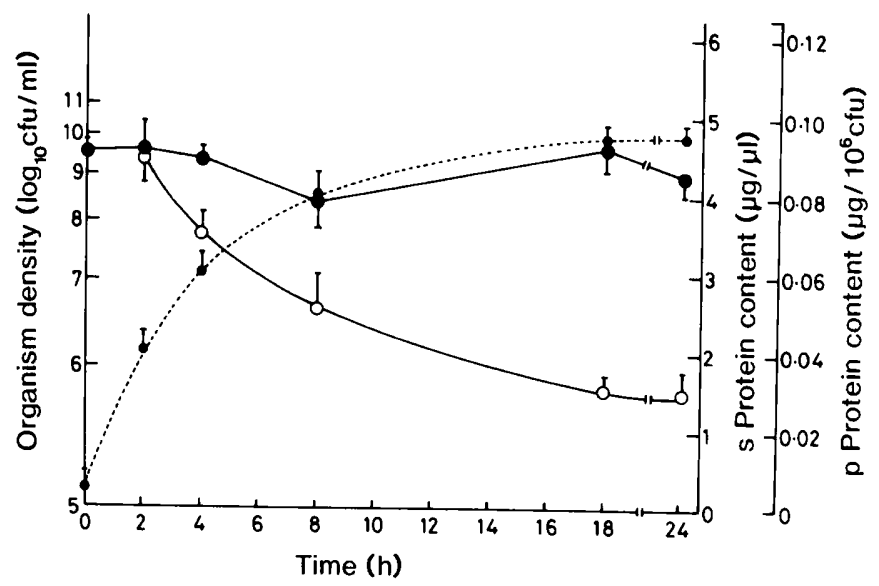

Fig. 1. Age of culture and age-dependent changes in supernate (s) and pellet (p) protein concentrations of $P$. aeruginosa. Each point is the mean (bar $=\mathrm{SD})$ of 3 or 4 separate experiments. 


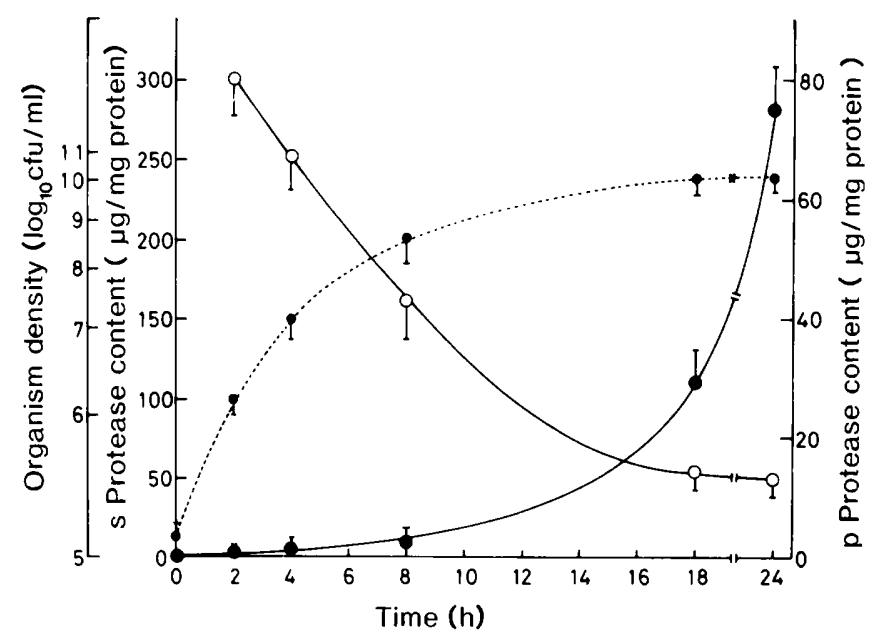

Fig. 2. Changes in contents of supernate (s) and pellet (p) intracellular proteases of $P$. aeruginosa in relation to the age of the culture. Each point is the mean $(\mathrm{bar}=\mathrm{SD})$ of 3 or 4 separate experiments, $\mathrm{O}-\mathrm{O}$, p protease content.

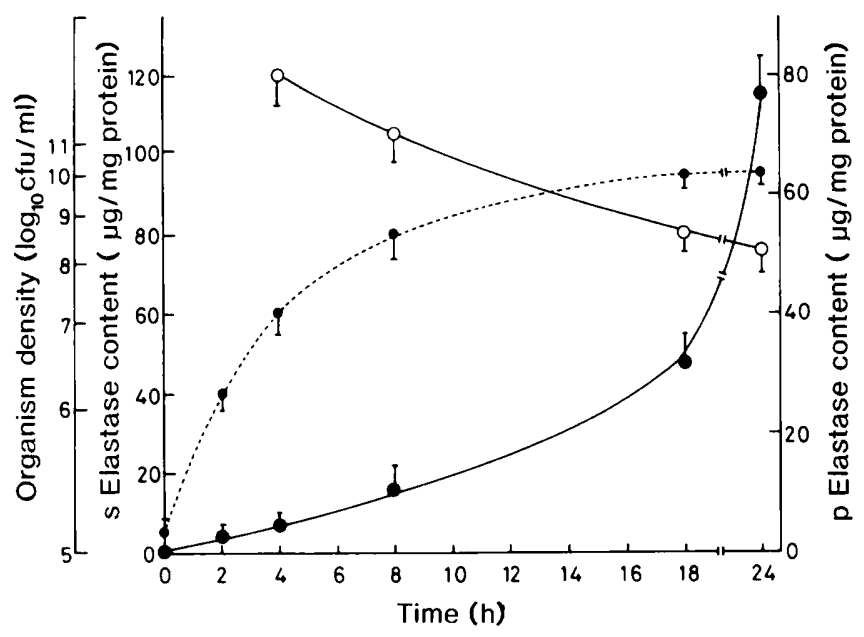

Fig. 3. Changes in contents of supernate (s) and pellet (p) intracellular elastases of $P$. aeruginosa in relation to the age of the culture. Each point is the mean (bar $=$ SD) of 3 or 4 separate experiments. $\mathrm{O}-\mathrm{O}$, p elastase content.

quently occur in patients with specific underlying diseases (Aduan and Reynolds, 1979). Once $P$. aeruginosa invades the lower respiratory tract, it multiplies at a rate influenced by the particular conditions of the pulmonary micro-environment, which include underlying diseases such as cystic fibrosis and bronchiectasis. P. aeruginosa is generally considered to adhere more frequently to the mucosal epithelial cells of hosts which have been colonised already than to those of non-colonised hosts (Christensen et al., 1985; Umeki, 1987). Longterm colonisation with $P$. aeruginosa runs parallel to the severity of the underlying disease and the difficulty of eradication of this micro-organism with antimicrobials. The present results suggest that a large volume of protease and elastase secreted extracellularly by $P$. aeruginosa during long-term colonisation may produce great damage to its hosts. The protease content in sputum from 14 patients with bronchiectasis and $P$. aeruginosa lung infection (Umeki, 1987) was also determined. The mean content of sputum protease was $85.7 \mathrm{mg} / \mathrm{mg}$ of protein, which is much greater (about 300 -fold) than the in-vitro extracellular protease in this study.

Specific colonisation mechanisms can be advantageous to the participants in a host- (or tissue-) 
pathogen relationship. Colonisation by a particular bacterial species may vary considerably according to the host species and tissue (Christensen et al., 1985) These conditions are known as host tropism and tissue tropism respectively. Extracellular pro-

\section{REFERENCES}

Aduan R P, Reynolds H Y 1979 The importance of cell-mediated responses to Pseudomonas infection. Doggett $\mathbf{R}$ (ed) In: Pseudomonas aeruginosa: clinical management of infection and current therapy. Academic Press, New York pp 135156.

Banno Y, Yano K, Nozawa Y 1982 Biochemical characterization of secreted proteases during growth in Tetrahymena pyriformis WH-14: Comparison of extracellular with intracellular proteases. Journal of Protozoology 29: 91-98.

Christensen G D, Simpson W A, Beachey E H 1985 Adhesion of bacteria to animal tissues: Complex mechanisms. In: Savage D C, Fletcher M M (eds) Bacterial adhesion: mechanisms and physiological significance. Plenum Press, New York, pp 279-305.

Feigin R D, Shearer W T 1975 Opportunistic infection in children. II In the compromised host. Journal of Pediatrics 87: 677-694.

Johnson G G, Morris J M, Berk R S 1967 The extracellular protease from Pseudomonas aeruginosa exhibiting elastase activity. Canadian Journal of Microbiology 13: 711-719.

Kanungo M S (ed) (1980) Biochemistry of ageing. Academic Press, New York, pp 79-128.

Kreger A S, Gray L D 1978 Purification of Pseudomonas aeruginosa protease and microscopic characterization of pseudomonal protease-induced rabbit corneal damage. Infection and Immunity 19: 630-648.

Lowry O H, Rosebrough N J, Farr A L, Randall R J 1951 Protein measurement with the folin phenol reagent. Journal of Biological Chemistry 193: 265-275.

Meinke G, Barum J, Rosenberg B, Berk R 1970 In-vivo studies tease and elastase may play an important role in establishing these host and tissue tropisms. Partial purification and characterisation of these proteases are currently under investigation in our division.

with the partially purified protease (elastase) from Pseudomonas aeruginosa. Infection and Immunity 2: 583-589.

Morihara K, Tsuzuki H 1977 Production of protease and elastase by $P$ seudomonas aeruginosa strains isolated from patients. Infection and Immunity 15: 679-685.

Morihara K, Tsuzuki H, Oda K 1979 Protease and elastase of Pseudomonas aeruginosa : inactivation of human plasma $\alpha_{1}$ proteinase inhibitor. Infection and Immunity 24: 188-193.

Rinderknecht H, Geokas M C, Silverman P, Haverback B J 1968 A new ultrasensitive method for the determination of proteolytic activity. Clinica Chimica Acta 21 : 197-203.

Sabath L D (ed) 1980 Pseudomonas aeruginosa: the organism, diseases it causes, and their treatment. H. Huber, Bern.

Umeki S, Fukushima H, Nozawa Y 1983 Variations in the activity of fatty acyl-CoA desaturases and electron-transport components in Tetrahymena microsomes with temperature and age of culture. Journal of Thermal Biology 8: 353360 .

Umeki S, Nozawa Y 1983 Effects of sterol manipulation on microsomal desaturase activities in Tetrahymena: with regard to thermal acclimation. Biochemical and Biophysical Research Communications 113: 96-101.

Umeki S 1987 Factors influencing bacterial adhesion in the respiratory tract. The 60th International Symposium on Infectious Diseases, Tokyo, 1987.

Woods D E, Straus D C, Johanson W G, Bass J A 1981 Role of salivary protease activity in adherence of gram-negative bacilli to mammalian buccal epithelial calls in vivo. Journal of Clinical Investigation 68: 1435-1440.

Wretlind B, Wadström T 1977 Purification and properties of a protease with elastase activity from Pseudomonas aeruginosa. Journal of General Microbiology 103: 319-327. 